\title{
A new method of psychotechnical testing of transport operators
}

\author{
Katarzyna Chruzik $^{1, *}$, and Aleksander Korchut ${ }^{2}$ \\ ${ }^{1}$ WSB University, Department of Railway Transport, Dąbrowa Górnicza, Poland \\ ${ }^{2}$ GPE Psychotronics, Tychy, Poland
}

\begin{abstract}
New expectations in the field of psychotechnical tests and screening of transport operators has led to the improvement of theoretical foundations and increase in quality of the psychological judicature, which has proved to be challenging to the scientific units and health centers. The purpose of the abovementioned adjudicating is to determine the existence or the absence of the contraindications to drive a vehicle or to perform the duties of an instructor or an examiner. This is particularly difficult in case of the branch of unit based transport (that is road transport) where the results of the emergencies are usually incomparably lesser than in others means of transport (air, rail, sea). These tests have been presented only from the perspective of professional transport operators and their range is limited. The publication contains the description of a new methodology of testing transport operators with the use of a device that allows to determine the level of functional efficiency of the nervous system and the correlation of mental processes (such as the efficiency of cognitive, intellectual, and psychomotor functions and selected personality features, temperament) with the physiological parameters (pulse, GRS etc.) - that is Psychotronics. This device allows to diagnose the psychomotor efficiency of people employed in professions requiring special psychomotor vigilance and human activity where current psychological possibilities determine the life and safety of others.
\end{abstract}

\section{Introduction}

Psychological diagnostics carried out in the work psychology laboratories of transport operators consists of the methods used in clinical proceedings, namely: interview, observation and various standardized scales and personality, temperament or intelligence questionnaires whose results are often burdened with social approval [1]. At the same time, it consists of tools for measuring psychomotor and perceptual skills. Thus, various types of devices for measuring reaction time, motor or visual skills. Their structure, often based on solutions that have been outdated by the dynamic development of computer technology, is not compatible with contemporary methodological standards. A psychological test is a tool that allows to obtain a representative sample of behaviors that can be assumed to be indicators of the psychological characteristic that interests us.

\footnotetext{
* Corresponding author: kchruzik@,wsb.edu.pl
} 
The presented work features the possibilities and scope of application of the Psychophysiological Diagnostic System with the abbreviated name Polipsychograf. It is a modern set for constructing experiments in the field of psychophysiological diagnostics. The integrated variable measurement system in the field of cognitive and psychomotor performance with simultaneous measurement of physiological parameters is a proposition not only for transport psychology, but also for medicine, pharmacology and other areas in which the overall assessment of human functioning is taken into account. Research conducted in this area indicates the possibility of treating the general cognitive performance of the individual as the main predictor of the level of tasks and effectiveness of training that requires psychomotor skills such as rapid response to stimuli, proper sensorimotor coordination, as well as fast and accurate visual perception [2]. The psychological research model presented in the publication is a response to the growing requirements in this area while limiting the costs and time of diagnostics of transport operators. As part of scientific research, the level of psychomotor efficiency of the test group of road operators (vehicles drivers) determined by means of typical transport tests (Piórkowski-type machine) was compared with the results obtained with the help of the device to determine the level of functional efficiency of the nervous system and correlation of cognitive processes with physiological parameters.

\section{The system of psychophysiological variables measurement}

The use of measuring equipment in psychological research was inspired by the dynamic development and attractiveness of neuropsychological knowledge. The need to reach deep into our mind, the curiosity to know its structure and the mechanisms of action, required the use of a new kind of non-invasive methods. In the medical sciences, this role was taken over by computed tomography, electromagnetic resonance or ultrasonography. While these methods precisely illustrate the structure of our organs, their functioning requires a lot of additional research, including e.g. biochemical tests or specific interview [3].

Understanding the functional efficiency of the nervous system by measuring variables relating to cognitive and psychomotor functions, integrated in time with parallel measurement of physiological parameters [4], was the main goal of undertaking interdisciplinary research, which is still being continued. The large variation in research results as well as the statistical analyzes collaborate the main assumptions of the project and the validity of the applied research tools, while encouraging the continuation of the conducted research. The inspiration and methodological support has been, popular in recent years, the micro genetic theory of brain function, developed by American neurologist and neuropsychologist Jason W. Brown [5], which enables understanding of changes in both thinking and behavior under the influence of various diseases, pharmaceuticals used in their treatment, as well as processes that are the result of stress or aging of the body.

Human behavior is a derivative of the course of the mental process, which begins in the deepest, and at the same time oldest, layers of the nervous system and gradually evolves through the next, higher located, younger layers, and reveals in the form of motor reactions or other forms of behavior. Because the whole process "happens" at the time of the microscale, Brown gave the developed concept the name of the theory of micro genetic function of the brain. According to it, human behavior is the reproduction of the whole ontogenetic process within a few milliseconds. In the case of brain damage, the process becomes stratified and, as a result, it emerges too early from the deeper level hidden in typical behavior [6]. Thus, the disease symptom is not an erroneous behavior but a proper accomplishment of a task in the form of a less developed level.

The original part of this theory is to deny the general opinion that defines the process of perception as the inverse of the reaction process. According to it, in the process of 
perception, information reaches our brain from the outside and the reactions "get out". According to Brown, the perception takes place inside the brain. In other words, we see and hear only those stimuli that the brain allows (selects) to pick up. Objects and phenomena that we perceive, exist in our brain in the form of mental images, just like imaginary processes that are a reflection of our statements. The key element of the micro genetic theory is to focus on the evolution of mental processes, that is, the passing of subsequent changes. In the traditional approach, the diagnostician tries to describe the condition of the subject, defining particular variables and their parameters. He assigns specific numerical values to them, although every clinician knows that the condition described at the moment most often does not exist anymore. According to Brown, we should concentrate on the analysis of the evolution process, which is carried out in the subject and possible symptoms to be seen in the context of specific stages of evolution that occurred as a result of brain damage [7]. As the process is being learnt, the brain organizes its resources so that specialized centers gradually take over those functions that they perform best and most efficiently. In the ontogenetic development the brain evolves similarly. As we age, certain functions become gradually focused in individual centers, which in case of damage to a given area causes completely different symptoms in a young person and an older person.

The research project was based on the interpretation of the psychological measurement results close to theories of the micro genetic function of the brain, which assumes the dynamic treatment of clinical data. Relating to inter-individual norms is not as important as the analysis of the dynamics of changes taking place in the examined person. The research used the Psychophysiological Diagnostics and Rehabilitation System called Polipsychograph. It is dedicated to design and carry out psychological tasks testing the mental, cognitive and motor skills of a human being in connection with the assessment of his professional abilities or the diagnosis of possible deficits of various origins. The tested skills are recognized in the context of the accompanying reactions and physiological processes manifesting themselves through changes in their value, which allows additional interpretation of the obtained data. The second, next to the diagnostic function of the device is stimulation with appropriate configurations of stimuli and commands of people who need to improve the above due to deficits, damage or losses in the field of psychomotor functions. In both cases, apart from a ready set of test and rehabilitation tasks, it is possible to independently design your own test or rehabilitation tasks (considering their substantive content, form, presentation rhythm, etc.). Thanks to this, it is possible to individualize the diagnostic or rehabilitation process and to eliminate the possibility of training. The device can also be used for testing research hypotheses in scientific research in the field of psychophysiology. The system consists of three basic elements. These are: a computer (portable or stationary), a control program, a Psycho-physiological status meter - Figure 1. In the system, the computer has the functions of programming and controlling both the diagnostic and therapeutic processes. Its software enables flexible selection of test tools depending on the studied sphere and is open in nature. This means that they can be gradually expanded with new applications or we can modify the existing ones. The psychophysiological parameter meter is basically just a peripheral device. The psychologist conducting the research works with the control computer. However, the basic function of the software is to run the test on the screen of the meter, and after its completion presentation and analysis of the results.

The proposed diagnostic system is based on new solutions in the field of psychophysiological equipment. An unquestionable advantage of the system is its openness and the possibility of modular expansion depending on the needs and establishing a list of variables relevant to the course of a given process. This approach allows to extend the scope of application of the tool, making it more flexible in practical applications both in the 
conditions of an individual diagnostic laboratory (psychological, physiological, medical, ergonomic) as well as scientific and research laboratories.

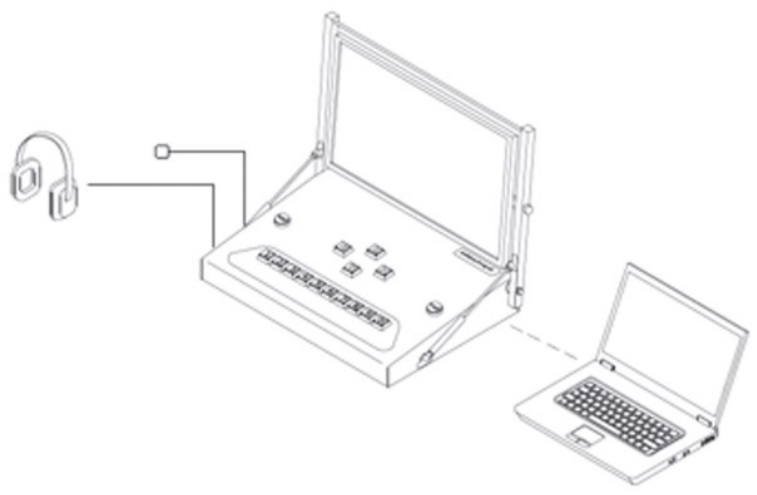

Fig. 1. System of Psychophysiological Diagnostics.

Previous practice related to the use of the system supports the continuation of implementation research, mainly based on the improvement of exposed tests, their diagnostic and rehabilitation value, with particular emphasis on elderly people. Undertaking further work on the system is not burdened with the risk of duplicating similar solutions in relation to psychological and medical issues. However, the previous use of the discussed apparatus (without measuring physiological processes) for scientific purposes confirms the reasonableness of the adopted assumptions.

\section{Analysis of visual-motor coordination of vehicle drivers}

As part of comparative studies, an analysis of the condition of visual and motor coordination of a group of transport operators - driving vehicles (representative age to obtain the most favorable results - 20-30 years) was performed. The tests were carried out on a typical device used in diagnostics (Piórkowski-type machine) and Polipsychographs.

Piórkowski's apparatus is one of the first devices used for the diagnosis of visual and motor coordination of upper limbs as well as the properties of motor reactions. It was established at the turn of the century. In its current form it consists of a front panel on which, in a horizontal arrangement, there are - 10 diodes emitting light stimuli and ten buttons located beneath them, enabling reception of reactions - Figure 2. The examined person should react to the light stimulus by pressing the appropriate button as quickly as possible (the reaction must occur during the light exposure). The microprocessor counts the correct reactions of the examined person. The tests included 90 pulses presented in 60 seconds.

The short use of available online resources allows for detailed familiarization with this method, and in cases of high pressure related to diagnostics, to simulate the study environment, and thus the possibility to train the response. Therefore, the research may have been subject to errors for a long time.

Diagnosis using the Polipsychograph was based on five simple tests, the structure of which can be changed at any time by the researcher. The research included the Add Test - a test task based on simple mathematical operations that are difficult to remember. The test is used to study the pace and correctness of thinking. Simple arithmetic operations are the operations composed of two single-digit numbers, e.g. $5+2$. Performing these activities is associated with mental representations of numbers and specific cognitive processes. The general model of processing numbers and making calculations according to McCloskey [8] 
is based on three specialized systems: numerical understanding, computational and number generation. These systems are based on the internal representation of numbers (meaning of the number $=$ size of the number). These studies were carried out on two slightly different models to verify the effect of training. The following tests are Numbers Test - a computer adaptation of a popular cognitive method for simple cognitive processes: concentration, attention and operational memory - and Line Test - a method of measuring the efficiency of visual perception with simultaneous measurement of the visual acuity level. The results in the test show a decrease in the correct answers in the second test. Attention becomes less selective after a lot of physical effort. Then a simple coordination test was carried out - a modified version of the method popular among psychologists to study visual and motor coordination and precision of movements. The device records reaction times, specifying the average, minimum, maximum and percentage of efficiency. It differentiates reactions to: correct, incorrect, late. The last test carried out concerned complex coordination - the method of measuring visual-motor coordination and precision of movements, extended by the element of thought.

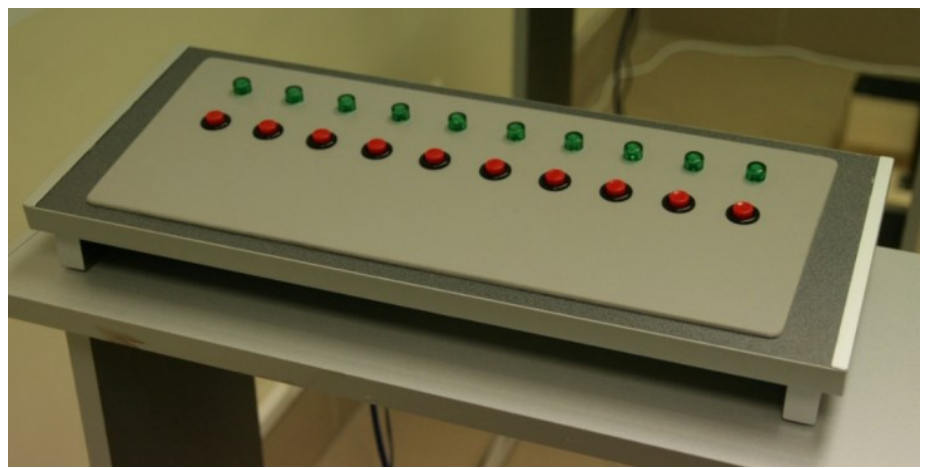

Fig 2. A modified version of the Piórkowski's Apparatus.

As part of the diagnostics using Piórkowski's apparatus, after the first tests, the operators were allowed to resume the tests until the favorable results were achieved - Fig. 3-4. The conducted statistical analysis, even for reasonable coordination requirements $(60 \mathrm{~s}$, 90 impulses) shows a significant and rapid improvement of the reaction and, consequently, the possibility of falsifying opinions in the field of professional transport operators. The learning curve shows the sensitivity associated with boredom, but has a clear upward tendency - Figure 5.

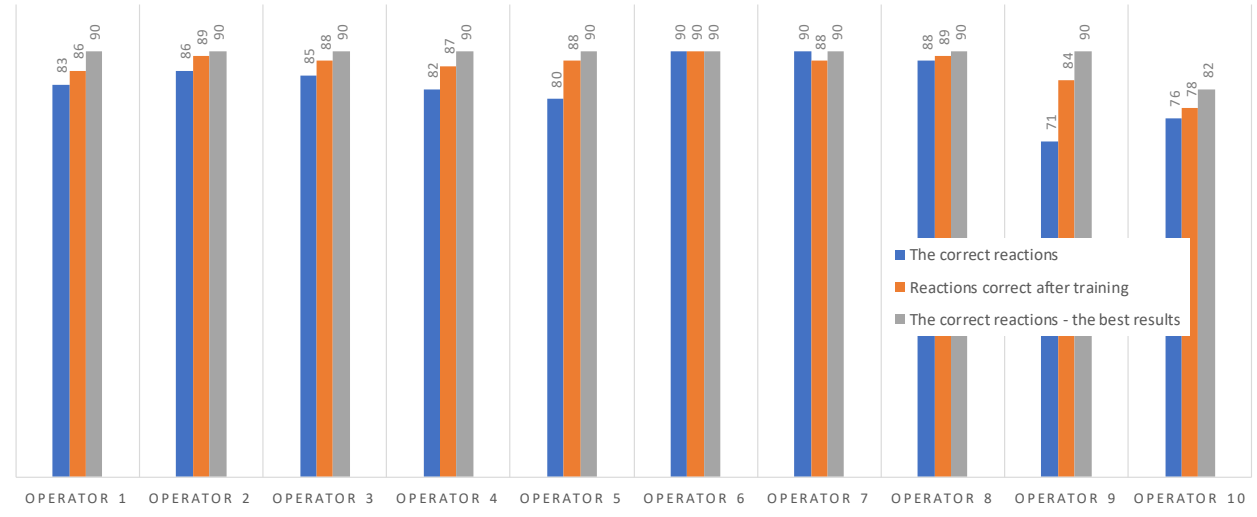

Fig 3. Piórkowski’s Apparatus -correct reactions graph. 


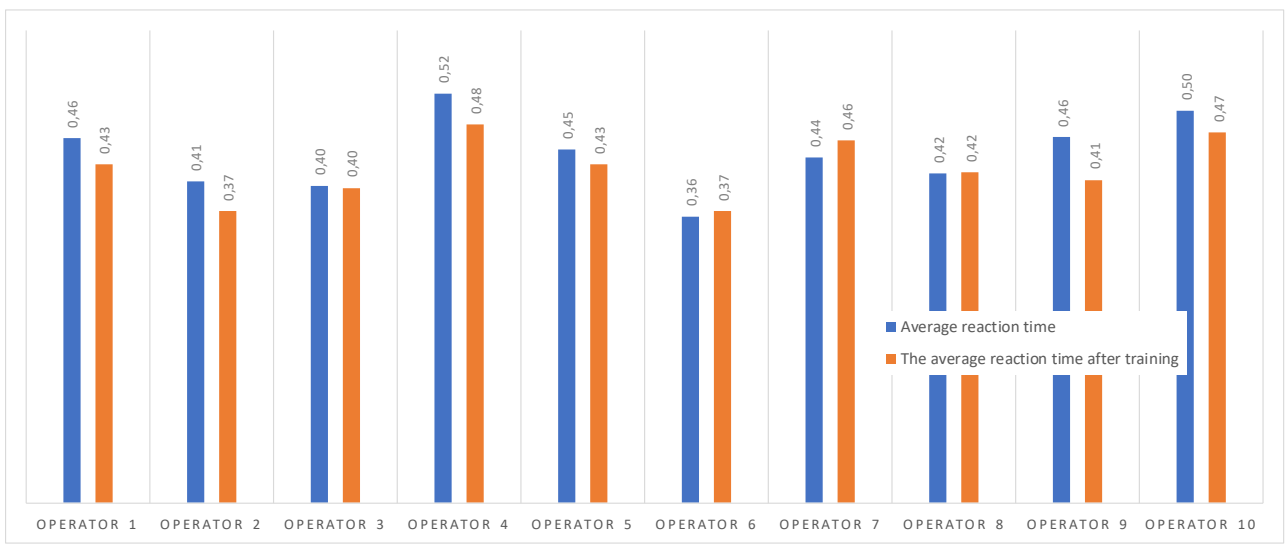

Fig 4. Piórkowski’s Apparatus- average reaction time

a)

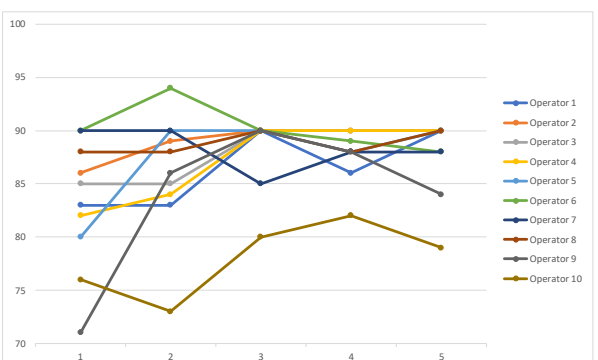

b)

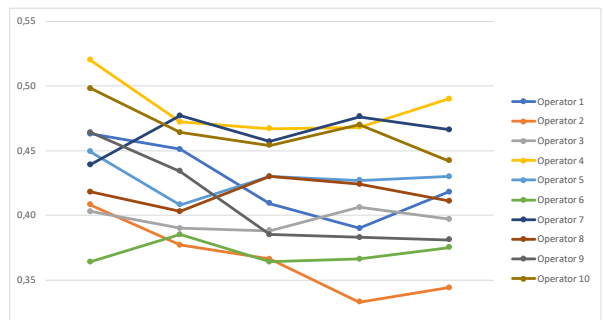

Fig 5. Learning curve: a) number of correct responses b) average reaction time.

As part of the diagnostics using the Psychophysiological Diagnosis System Polipsychograph, the tests confirmed the possibility of rapid modification of the test that prevented the introduction of the training effect. In terms of the group of transport operators being examined, the correct value of eye-hand coordination was demonstrated with the analysis of the elements of visual acuity, correctness of logical and spatial thinking, which is an additional advantage of the method.

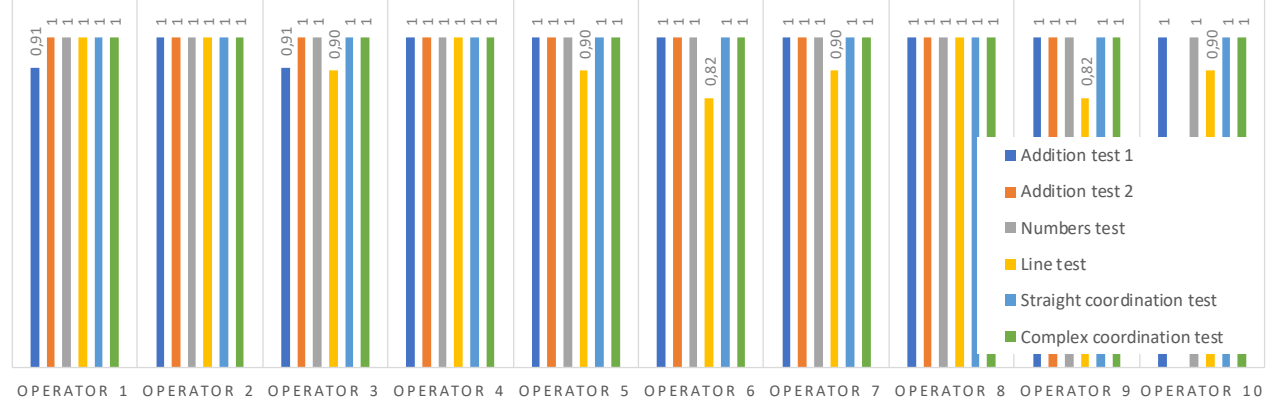

Fig 6. System of Psychophysiological Diagnostics - test success rate (max 1). 


\section{Conclusions}

The application of the new test method in practice allows for a realistic assessment of the current psychophysical condition of transport operators, eliminating the currently occurring factor related to the training. This training may be due to a limited number of available diagnostic methods and the need to carry out periodic diagnostics. Currently available and used diagnostic methods do not take full account of the changes that have taken place in the very nature of the profession [9]. Changes regarding the construction of machines, available modern control and service solutions. The dynamic development of applied technology somehow forces the necessity to create diagnostic methods that the researcher / diagnostician will be able to adjust with greater freedom to the purpose of the research. In some cases, it will be possible to repeat the test in a short period of time with the exclusion of the effect of learning, and in other cases to match the method of answering the test subject's abilities without changing the task material. It is also worth mentioning that the labor market, also susceptible to this development, puts increasingly higher demands on candidates or employees [10]. The use of universal methods in the recruitment process for a specific position may constitute a certain limitation. The use of modern diagnostic methods based on computer systems in diagnostics and psychological rehabilitation creates the possibility of constructing modern, interesting and modifiable tools enriching both the psychologist's workshop, facilitating the collection and processing of the obtained data. Such methods also have significant benefits for patients for whom they are $[11,12]$. Computer-aided cognitive rehabilitation shows a significant sadistic difference in the effectiveness of work and improvement of the cognitive functioning of patients after stroke [13], where it is so important that the task, or rather the method of its solution, is tailored to the person's ability, health and psychomotor performance. The speed and ease of testing may in the future allow verification of the status of people employed in professions requiring special psychomotor skills (transport operators) even directly before the start of the process, thus limiting the sources of risks.

\section{References}

1. A. Łuczak, A. Tarnowsk, Artefacts of questionnaire-based psychological testing of drivers (in Polish), Med. Pr. 65 pp. 373-385 (2014). doi:10.13075/mp.5893.2014.036

2. T.R. Carretta, M.J. Ree, General and Specific Cognitive and Psychomotor Abilities in Personnel Selection: The Prediction of Training and Job Performance, Int. J. Sel. Assess. 8 pp. 227-236 (2000). doi:10.1111/1468-2389.00152

3. K. Krupka, W. Korchut, Psychologia i medycyna w zawodach trudnych i niebezpiecznych (Psychotronics Publishing, Komisja Nauk Psychologicznych PAN, Katowice, Poland, 2017)

4. W. Korchut, SDP - psychophysiological diagnostic system. Ergonomics and work safety in information community (Education and researches, Poznań, Poland, 2005)

5. J.W. Brown, Neuropsychology of visual percepction (Hillsdale. NJ: LEA, 1989)

6. A.R. Łuria, Podstawy neuropsychologii (PZWL, Warsaw, Poland, 1976)

7. M. Pąchalska, B.L.J. Kaczmarek, J.D. Kropotov, Neuropsychologia kliniczna. Od teorii do praktyki (Wydawnicto Naukowe PWN SA, Warsaw, Poland, 2014)

8. M. McCloskey, A. Caramazza, A. Basili, Cognitive mechanisms in number processing and calculation: Evidence from dyscalculia, Brain Cogn. 4 pp. 171-196 (1985). doi:10.1016/0278-2626(85)90069-7 
9. M. Ucińska, M. Niezgoda, Nowe perspektywy dla psychologii transportu w diagnostyce i badaniach naukowych, Transp. Samoch. 3 pp. 17-32 (2012)

10. D. Jankowska, I. Leśnikowska-Matusiak, Współczesne metody uczenia się ludzi dorosłych i ich wykorzystanie w edukacji bezpieczeństwa ruchu drogowego, Logistyka. 3 pp. 971-9 (2011)

11. C. Yoo, M.-H. Yong, J. Chung, Y. Yang, Effect of computerized cognitive rehabilitation program on cognitive function and activities of living in stroke patients, J. Phys. Ther. Sci. 27 pp. 2487-2489 (2015). doi:10.1589/jpts.27.2487

12. Sylwia Chładzińska-Kiejna, Monika Wiłkość, Sylwia Adamowska, Computerized methods of neuropsychological diagnosis and rehabilitation, Psychogeriatria Pol. 10 pp. 127-136 (2013)

13. I.-S. Park, J.-G.J.-G. Yoon, The effect of computer-assisted cognitive rehabilitation and repetitive transcranial magnetic stimulation on cognitive function for stroke patients., J. Phys. Ther. Sci. 27 pp. 773-6 (2015). doi:10.1589/jpts.27.773 